\title{
Interaction of Arbuscular Mycorrhizal Fungi and Trichoderma on Growth of Root System and on Yield of Industrial Hemp (Cannabis sativa var. 'Uso')
}

\author{
Ioanna KAKABOUKI, Dimitrios TSIROGIANNIS, Stella KARYDOGIANNI, Antigolena FOLINA, Charikleia \\ ZISI, Emmanouil PLATANOPOULOS, Giorgos PAPADOPOULOS, Gerasimos GRAMMENOS, Dimitrios \\ BILALIS*
}

Agricultural University of Athens, School of Agriculture, Engineering and Environmental Sciences, Dpt. of Crop Science, Laboratory of Agronomy, 75 Iera Odos Street, 11855 Athens, Greece

*corresponding author: bilalis@aua.gr

BulletinUASVM Horticulture 77(2) / 2020

Print ISSN 1843-5254, Electronic ISSN 1843-5394

DOI:10.15835/buasvmcn-hort: 2020.0053

\begin{abstract}
Cannabis sativa is an annual herbaceous plant, known worldwide for thousands of years. The propose of this study was to evaluate the effect co-inoculation of Trichoderma harzianum and arbuscular mycorrhizal fungi (AMF) on growth of root system and yield in plants of industrial cannabis variety 'Uso'. A greenhouse experiment took place in the Laboratory of Agronomy at Agricultural University of Athens. The experiment was designed according to Randomized block design with 2 treatments AMF \& Trichoderma (AMF\&TRCH) application and Trichoderma without AMF application (TRCH) and 3 replications. Trichoderma species have the ability to colonize the rhizosphere of plants, thereby improving the development of the root system. Arbuscular mycorrhizal fungi can form symbiotic relationships with most plants, including species of great economic interest such as industrial hemp. The combined use of Trichoderma harzianum and AMF provoked a synergistic effect increasing the root mass density, bud length and CBD yield per plant. During AMF\&TRCH treatment the number of buds, bud dry matter and yield were higher than the TRCH treatment, on the contrary AMF colonization and root volume decreased. In conclusion the supply of AMF\&Trichoderma had positive effect on AMF percentage, root and agronomic characteristics.
\end{abstract}

Keywords: agronomic characteristics, arbuscular mycorrhizal fungi (AMF), Cannabis sativa, root system, Trichoderma

\section{Introduction}

Cannabis sativa $\mathrm{L}$. is an annual herbaceous plant, grown mainly in Central Asian countries (Russo et al., 2008) having various uses over the years such as in textiles, food, oils and medicines (Piluzza et al., 2013). Fiber hemp is grown for a variety of end products derived from cannabinoids, seeds, fibers (Papastylianou et al., 2018). Central Asia and Southeast Asia are mentioned as potential areas for the natural origin and/or primary domestication of $C$. sativa (Stevens et al., 2016). Also, Neolithic pieces of evidence found in Taiwan suggest that $C$. sativa 12,000 years ago was used (Li, 1974) and its role in the textile manufacturing was important.

It is well known that Trichoderma species have the ability to colonize the rhizosphere of plants, thereby improving the development of the root system as well as the systemic defenses. Trichoderma spp. has been known for about 70 years to be able to attack other fungi, produce antibiotics and act as biological control microbes (Weindling and Fawcett, 1936). It is worth note that these fungi often increase plant growth and 
productivity (Lindsey and Bake, 1967) either in the presence (Chang et al., 1986) or in the absence (Lindsey and Bake, 1967) of other microorganisms and that they can cause disease suppression in soils (Chet and Bake, 1981). Arbuscular mycorrhizal fungi (AMF) is one of the most important beneficial soil microbiota that can be grown in the laboratory and coexist closely with plants in the last 455 million years (Redecker et al., 2000). It seems that the AMF thrives in soils where there is organic matter (Albertsen et al., 2006). In addition, arbuscular mycorrhizal fungi can form symbiotic relationships with most plants, including species of great economic interest such as industrial hemp. However, interaction between AMF and Trichoderma affects AMF development (Rodriguez et al., 2006). Mycorrhizal fungi are the direct link between soil and plant roots (Haselwandter et al., 1994). The formation of mycorrhizal associations can compound to improve the nutritional status of the plant (Turnau, 1998).

The aim of the present study was to evaluate the effect of co-inoculation of Trichoderma harzianum and arbuscular mycorrhizal fungi (AMF) on growth of root system and plant yield of industrial cannabis variety 'Uso'.

\section{Materials and Methods}

A greenhouse study was carried out in Agronomy Laboratory of the Agricultural University of Athens (Southern Greece, latitude: 3758' N, longitude: $23^{\circ} 32^{\prime} \mathrm{E}$, altitude $30 \mathrm{~m}$ above sea level) from April 10, 2020 to June 20, 2020. Seedlings of Cannabis sativa var. 'Uso' planted in pots (the size of the pots were $12 \mathrm{~L}$ ) which filled with soil and compost (8 L compost per pot) (Tab. 1) and inoculated with Trichoderma harzianum (Trianum-P by Koppert) \& AMF (mixture from species Gloms spp: Glomus spurcum, Glomus mosseae, Glomus geosporum, Glomus clarum, Glomus etunicatum by EctoMyc). The experiment was set up according to Randomized block design with 2 treatments AMF and Trichoderma (AMF and TRCH) application and Trichoderma without AMF application (TRCH) and 3 replications. The amounts added were $2 \mathrm{ml} \mathrm{pot}^{-1}$ Trichoderma and $2 \mathrm{~g} \mathrm{pot}^{-1} \mathrm{AMF}$.

The measurements of root characteristics (root mass density, diameter, volume) and colonization of AMF were done in the flowering period while bud dry matter, yield, bud length, compact index, CBD content, were done at the end of the growing season (about 110 DAS). The plant height was at 20, 90 and 110 DAS, while the dry matter of plants 25, 50, 70, 90 and 110 DAS. Concerning the root measurements, 4 samples per treatment were collected. Root samples were collected from the 0-35 cm layer by using a cylindrical auger (25 $\mathrm{cm}$ length, $10 \mathrm{~cm}$ diameter). They were washed over a $5 \mathrm{~mm}$ mesh sieve. Also, there was used a formalin/acetic acid/alcohol (FAA) staining solution. Root mass density (cm of root $100 \mathrm{~cm}^{-3}$ soil), root diameter $(\mathrm{cm})$, as well as root volume $\left(\mathrm{cm}^{3}\right.$ of root $100 \mathrm{~cm}^{-3}$ soil) were determined in millimeters using a high resolution scanner, using DT-software (Delta-T Scan version 2.04; Delta Devices Ltd, Burwell, Cambridge, UK) (Kokko et al., 1993; Bilalis et al., 2012). The percentage of root length colonized by AM fungi was measured microscopically by the grid line section method at 30-40× magnification (Giovannetti and Mosse, 1980). Additional for CBD, ten inflorescences were from each treatment and the CBD content was calculated using the GemmaCert device machine (GemmaCert Ltd., Israel).

The experimental data analysis was conducted using the Statistica software (StatSoft, 1996), according to the completely randomized design. Differences among the means were compared

Table 1. Soil and compost analysis

\begin{tabular}{lcc}
\hline \multicolumn{1}{c}{ Character } & $\begin{array}{c}\text { Soil - Clay Loam } \\
\mathbf{( 2 9 . 3 \%} \text { Clay, 33.8\% Silt, 36.9\% Sand) }\end{array}$ & Compost \\
\hline $\mathrm{pH}$ & 7.36 & 7.6 \\
\hline Olsen - P (mg kg & & 410 \\
\hline $\begin{array}{l}\text { Available potassium }(\mathrm{K}) \\
\text { (mg kg-1 }^{-1} \text { soil) }\end{array}$ & 15 & 620 \\
\hline Organic matter (\%) & 215 & 42.41 \\
\hline
\end{tabular}


using the Least Significant Difference (LSD) test, at the $5 \%$ level of significance $(P \leq 0.05)$.

\section{Results and Discussion}

The combined use of Trichoderma harzianum and AMF provoked a synergistic effect increasing the root mass density (Tab. 2), bud length and CBD yield per plant (Tab. 3). Also, the root volume in AMF\&TRCH treatment was $0.26 \mathrm{~cm}^{3} 100 \mathrm{~cm}^{-3}$ soil higher than root volume in TRCH treatment (Tab. 2). On the contrary AMF colonization and root volume decreased in TRCH treatment (Tab. 2). In addition, AMF\&TRCH are mentioned as effective factors for the development of the root system as well as for the uptake of nutrients (Szczałba et al., 2019). Zubek et al. (2012) observed that in the medicinal plants the intensity of $\mathrm{AMF}$ colonization ranging from $1.27 \%$ to $78.8 \%$ where the lowest value found in Cannabis sativa. In our study the percentage of AMF in both treatments was higher $26.33 \%$ and $22.66 \%$ respectively, variety and growing conditions may be the factors that contributed to these results. Yaseen et al. (2016) noted that the Cannabis sativa was one of the species where high concentration of AMF spores were found in the soil surrounding its roots. According to the results of this study, the combination of AMF\&TRCH significantly affected the growth characteristics of plants such as number of buds, plant height with the highest value being $199.67 \mathrm{~cm}$ at 110 DAS (Tab. 2) and dry matter.

Concerning the dry matter per plant, the highest value, which was 218 g plant 1 , observed in AMF\&TRCH treatment at 90 DAS (Fig. 1). In addition, Martínez-Medina et al. (2009), observed a competitive effect on Trichoderma by AMF in melon plants (Cucumis melo L.).

Moreover the yield per plant, had higher values in AMF\&TRCH than in TRCH $168.08 \mathrm{~g}$ plant ${ }^{-1}$ and 150.39 g plant $^{-1}$ respectively (Tab. 3). AMF\&TRCH treatment leaded to higher number of buds, bud dry matter and yield than the TRCH application. On the other hand, CBD content was more affected in Trichoderma treatment without AMF where the value was $2.57 \%$, while in the application with AMF\&TRCH was $2.46 \%$. Similar results were shown in compact index, where the values were $1.18 \mathrm{~g} \mathrm{~cm}^{-1}$ and $1.33 \mathrm{~g} \mathrm{~cm}^{-1}$ respectively (Tab. 3). In general, Trichoderma provides root growth (Harman 2000).

Table 2. The root characteristics, AMF and plant height as affected by different treatments

\begin{tabular}{|c|c|c|c|c|c|c|c|}
\hline Treatments & $\begin{array}{c}\text { R mass density } \\
\text { (cm of root } 100 \\
\text { cm }^{-3} \text { soil) }\end{array}$ & $\begin{array}{l}\text { R diamet } \\
\text { (cm) }\end{array}$ & $\begin{array}{c}\mathrm{R} \text { volume } \\
\left(\mathrm{cm}^{3} \text { of root }\right. \\
100 \mathrm{~cm}^{-3} \\
\text { soil) }\end{array}$ & $\begin{array}{l}\text { AMF } \\
(\%)\end{array}$ & $\begin{array}{l}\text { Plant } \\
\text { Height } \\
\text { (cm) } \\
20 \text { DAS }\end{array}$ & $\begin{array}{l}\text { Plant Height } \\
\text { (cm) } \\
90 \text { DAS }\end{array}$ & $\begin{array}{c}\text { Plant } \\
\text { Height } \\
\text { (cm) } \\
\text { 110 DAS }\end{array}$ \\
\hline AMF \& TRCH & $0.07^{\text {ns }}$ & $0.20^{\mathrm{ns}}$ & $0.26^{\mathrm{a}}$ & $26.33^{a}$ & $22.67^{a}$ & $154^{\mathrm{a}}$ & $199.67^{a}$ \\
\hline TRCH & 0.07 ns & 0.22 ns & $0.21^{\mathrm{b}}$ & $22.66^{\mathrm{b}}$ & $21.33^{a}$ & $140.33^{b}$ & $187.33^{b}$ \\
\hline$F_{\text {treatmen }}$ & $n s$ & $n s$ & $4.34^{*}$ & $15.25^{*}$ & $13.22^{*}$ & $165.8^{*}$ & $152^{*}$ \\
\hline
\end{tabular}

Note: Significance levels: ${ }^{*} \mathrm{P}<0.05{ }^{* *} \mathrm{P}<0.01$; ${ }^{* *} \mathrm{P}<0.001$; ns: not statistically significant at $\mathrm{P}=0.05$

Table 3. Agronomic characteristics of cannabis plants as affected by different treatments

\begin{tabular}{lccccccc}
\hline Treatments & $\begin{array}{c}\text { Bud } \\
\text { number }\end{array}$ & $\begin{array}{c}\text { DM /bud } \\
\text { (g bud }^{-1} \text { ) }\end{array}$ & $\begin{array}{c}\text { Yield } \\
\text { (g plant }^{-1} \text { ) }\end{array}$ & $\begin{array}{c}\text { Bud length } \\
\text { (cm) }\end{array}$ & $\begin{array}{c}\text { Compact } \\
\text { Index } \\
\text { (g cm }^{-1} \text { ) }\end{array}$ & $\begin{array}{c}\text { CBD content } \\
\text { (\%) }\end{array}$ & $\begin{array}{c}\text { CBD yield/ } \\
\text { plant } \\
\text { (g plant }^{-1} \text { ) }\end{array}$ \\
\hline AMF \& TRCH & $6.13^{\mathrm{a}}$ & $27.42^{\mathrm{ns}}$ & $168.08^{\mathrm{a}}$ & $23.33^{\mathrm{a}}$ & $1.18^{\mathrm{a}}$ & $2.46^{\mathrm{ns}}$ & $4.14^{\mathrm{a}}$ \\
\hline TRCH & $5.57^{\mathrm{b}}$ & $27^{\mathrm{ns}}$ & $150.39^{\mathrm{b}}$ & $20.33^{\mathrm{b}}$ & $1.33^{\mathrm{b}}$ & $2.57^{\mathrm{ns}}$ & $3.86^{\mathrm{b}}$ \\
\hline$F_{\text {treatment }}$ & $4.32^{*}$ & $n s$ & $181.2^{*}$ & $32.1^{*}$ & $5.6^{*}$ & $\mathrm{~ns}$ & $6.8^{*}$ \\
\hline
\end{tabular}

Note: Significance levels: ${ }^{*} \mathrm{P}<0.05 ;{ }^{* *} \mathrm{P}<0.01{ }^{* * *} \mathrm{P}<0.001$; ns $=$ not statistically significant at $\mathrm{P}=0.05$ ) 


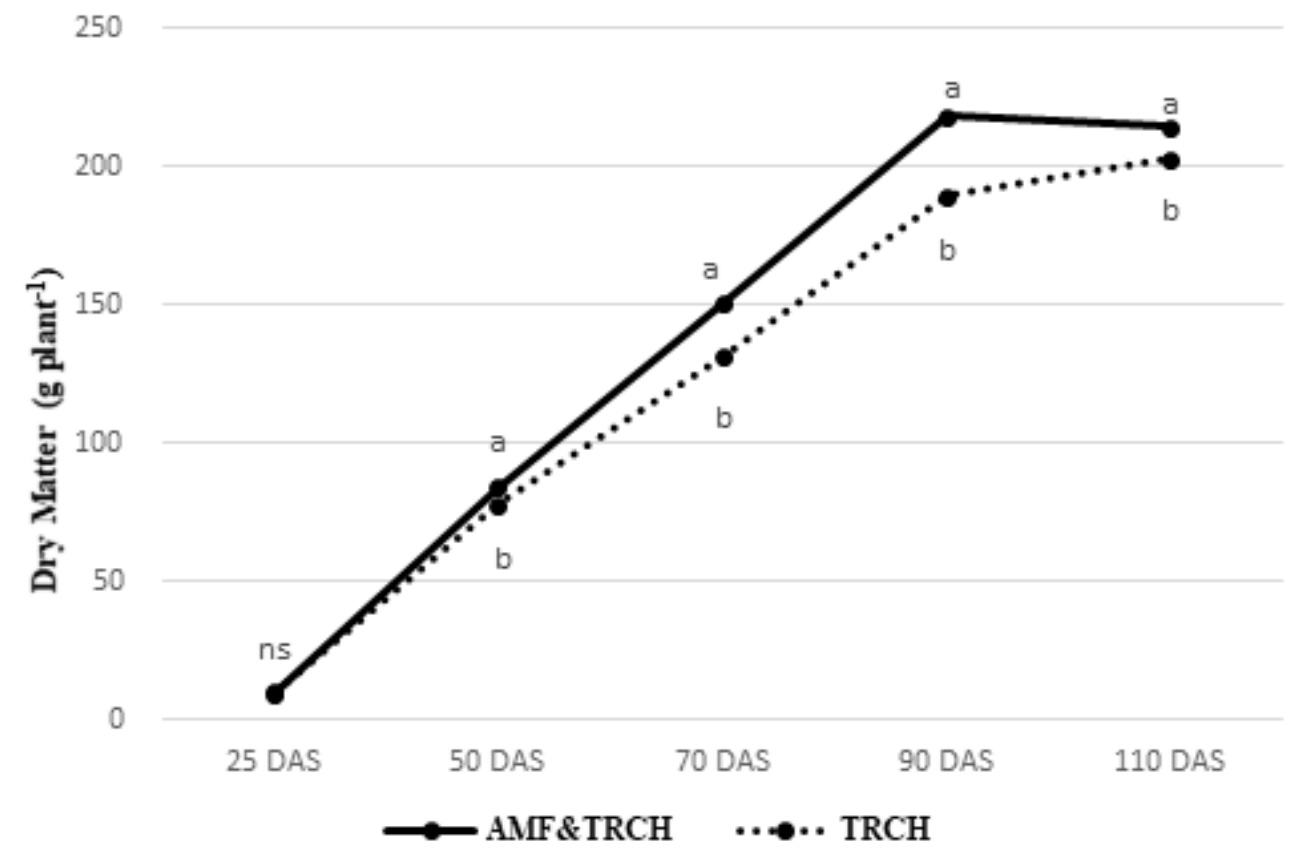

Figure 1. Dry matter of plants as affected by treatments, in different Days After Sowing (DAS) ns $=$ not significant at $\mathrm{P}=0.05$

\section{Conclusion}

To sum up, in the present research work, it was demonstrated that the simultaneous application of a Trichoderma biocontrol strain and AMF produces a significant increase in root system, such resulted in improved plant yield and CBD yield as well as in the other agronomic characteristics such as the plant height and the dry matter. On the contrary AMF colonization and root volume decreased in TRCH treatment.

\section{References}

1. Albertsen A, Ravnskov S, Green H, Jensen DF, Larsen J (2006). Interaction between the external mycelium of the mycorrhizal fungus Glomus intraradices and other soil microorganisms affected by organic matter. Soil Biology \& Biochemistry, 38:1008-1014.

2. Bilalis D, Katsenios N, Efthimiadou A, Efthimiadis $\mathrm{P}$, Karkanis A (2012). Pulsed electromagnetic fields effect in oregano rooting and vegetative propagation: A potential new organic method. Acta Agriculturae Scandinavica, Section B - Soil \& Plant Science, 62(1): 94-99.

3. Chang Y-C, Chang-C, Baker R, Kleifeld O, Chet I (1986). Increased growth of plants in the presence of the biological control agent Trichoderma harzianum. Plant Disease Journal, 70: 145-148.
4. Chet I, Baker R (1981). Isolation and biocontrol potential of Trichoderma harzianum from soil naturally suppressive of Rhizoctonia solani. Phytopathology, 71: 286-290.

5. Giovannetti M, Mosse B (1980). An evaluation of techniques for measuring vesicular arbuscular mycorrhizal infection in roots. New Phytologist, 84: 489-500.

6. Harman GE (2000). Myths and dogmas of biocontrol. Changes in perceptions derived from research on Trichoderma harzianum T-22. Plant Disease Journal, 84:377-393.

7. Haselwandter K, Leyval C, Sanders FE (1994). Impact of arbuscular mycorrhizal fungi on plant uptake of heavy metals and radionuclides from soil. In Impact of Arbuscular Mycorrhizas on sustainable agriculture and natural ecosystems, eds. S. Gianinazzi and H. Schüepp, 179-89. Basel: Birkhäuser Basel.

8. Kokko EG, Volkmar KM, Gowen BE, Entz T (1993). Determination of total root surface area in soil core samples by image analysis. Soil \& Tillage Research, 26: 33-43.

9. Li H (1974). An archaeological and historical account of Cannabis in China. Economic Botany, 28: 437-448.

10. Lindsey DL, Baker R (1967). Effect of certain fungi on dwarf tomatoes grown under gnotobiotic conditions. Phytopathology, 57:1262-1263.

11. Martínez-Medina A, Pascual JA, Lloret E, Roldán A (2009). Interactions between arbuscular mycorrhizal fungi and Trichoderma harzianum and their effects on Fusarium wilt in melon plants grown in seedling nurseries. Journal of the Science of Food and Agriculture, 89(11): 18431850. 
12. Papastylianou P, Kakabouki I, Travlos I (2018). Effect of Nitrogen Fertilization on Growth and Yield of Industrial Hemp (Cannabis sativa L.). Notulae Botanicae Horti Agrobotanici, 46(1):197-201.

13. Piluzza G, Delogu G, Cabras A, Marceddu S, Bullitta S (2013). Differentiation between fiber and drug types of hemp (Cannabis sativa L.) from a collection of wild and domesticated accessions. Genetic Resource and Crop Evolution, 60: 2331-2342.

14. Redecker D, Kodner R, Graham LE (2000). Glomalean fungi from the Ordovician. Science, 289: 1920-1921.

15. Rodriguez TS, Nieves JS, Gutiérrez EM, Cortés FS (2006). Arbuscular Mycorrhizae-Trichoderma harzianum (Moniliaceae) Interaction and Effects on Brachiaria decumbens (Poaceae)'s Growth. Acta Biológica Colombiana, 11(1): 43-54.

16. Russo EB, Jiang HE, Li X, Sutton A, Carboni A, del Bianco F, Mandolino G, Potter DJ, Zhao YX, Bera S, Zhang YB, Lü EG, Ferguson DK, Hueber F, Zhao LC, Liu CJ, Wang YF, Li CS (2008). Phytochemical and genetic analyses of ancient cannabis from Central Asia. Journal of Experimental Botany, 59: 4171-4182.
17. Stevens CJ, Murphy C, Roberts R, Lucas L, Silva F, Fuller DQ (2016). Between China and South Asia: a middle Asian corridor of crop dispersal and agricultural innovation in the bronze age. Holocene, 26: 1541-1555.

18. Szczałba M, Kopta T, Gastoł M, Sezkara A (2019). Comprehensive insight into arbuscular mycorrhizal fungi, Trichoderma spp. and plant multilevel interactions with emphasis on biostimulation of horticultural crops. Journal of Applied Microbiology, 127:630-647.

19. Turnau K (1998). Heavy metal content and localization in mycorrhizal euphorbia cyparissias from zinc wastes in southern Poland. Acta Societatis Botanicorum Poloniae, 67 (1): 105-13.

20. Weindling R, Fawcett HS (1936). Experiments in the control of Rhizoctonia damping-off of citrus seedlings. Hilgardia, 10(1): 1-16.

21. Yaseen T, Khan Y, Rahim F, Wali S, Ahmad I, Begum AH, Ghani SS (2016). Arbuscular mycorrhizal fungi spores diversity and AMF infection in medicinal plants of district charsadda khyber pakhtunkhwa. Pure and Applied Biology, 4 (4): 1176-82.

22. Zubek S, Błaszkowski J, Buchwald W (2012). Fungal root endophyte associations of medicinal plants. Nova Hedwigia, 94(3-4): 525-40. 